\title{
Hückel's Rule of Aromaticity Categorizes Aromatic closo Boron Hydride Clusters
}

\author{
Jordi Poater, ${ }^{[a, b]}$ Miquel Solà, ${ }^{*[c]}$ Clara Viñas, ${ }^{[d]}$ and Francesc Teixidor ${ }^{*[d]}$
}

\begin{abstract}
A direct connection is established between tridimensional aromatic closo boron hydride clusters and planar aromatic [n]annulenes for medium and large size boron clusters. In particular, our results prove the existence of a link between the two-dimensional Hückel rule followed by aromatic [n]-annulenes and Wade-Mingos' rule of three-dimensional aromaticity applied to the aromatic $\left[\mathrm{B}_{\mathrm{n}} \mathrm{H}_{\mathrm{n}}\right]^{2-}$ closo boron hydride clusters. Our results show that closo boron hydride clusters can be categorized into different series according to the $n$ value of the Hückel $(4 n+2) \pi$ rule. The distinct categories studied in this work correspond to values of $n=1,2$, and 3 . Each category increases in geometrical difficulty but, more importantly, it is possible to associate each category with the number of pentagonal layers in the structure perpendicular to the main axis. Category 1 has one pentagonal layer, category 2 has two, and category 3 has three.
\end{abstract}

\section{Introduction}

The most popular closo boron hydrides (BHs) are those that have a structure derived from the icosahedron. This particular structure provides a great chemical and physico-chemical stability. ${ }^{[1]}$ The most remarkable example within this class is $\left[\mathrm{B}_{12} \mathrm{H}_{12}\right]^{2-[2]}$ and the most extensively studied are the closocarboranes, result of replacing one or two $\mathrm{BH}^{-}$fragments by one or two $\mathrm{CH}$ groups. In this way, anionic and neutral carboranes are obtained, e.g. $\left[\mathrm{CB}_{11} \mathrm{H}_{12}\right]$, or ortho-, meta-, and para- $\mathrm{C}_{2} \mathrm{~B}_{10} \mathrm{H}_{12}$. At a large distance, in terms of number of scientific publications, there is the bicapped square antiprism, of which the most genuine example is $\left[\mathrm{B}_{10} \mathrm{H}_{10}\right]^{2-[3]}$ As for the case of icosahedra, $\left[\mathrm{B}_{10} \mathrm{H}_{10}\right]^{2-}$ transforms upon the replacement of one or two $\mathrm{BH}^{-}$by one or two $\mathrm{CH}$ groups into $\left[\mathrm{CB}_{9} \mathrm{H}_{10}\right]^{-}$or $\mathrm{C}_{2} \mathrm{~B}_{8} \mathrm{H}_{10}$, including their different isomers. In addition, besides the carbon heteroboranes, do exist a plethora of other heteroboranes, with heteroatoms such as S,

\footnotetext{
[a] Dr. J. Poater

Departament de Química Orgànica

Universitat de Barcelona

Martí i Franquès 1-11, 08028 Barcelona, Catalonia (Spain)

[b] Dr. J. Poater

Institució Catalana de Recerca i Estudis Avançats (ICREA)

Pg. Lluís Companys 23, 08010 Barcelona, Catalonia (Spain)

[c] Prof. Dr. Miquel Solà

Institut de Química Computacional i Catàlisi (IQCC) and

Departament de Química, Universitat de Girona

17071 Girona, Catalonia (Spain)

E-mail: miquel.sola@udg.edu

[d] Prof. Dr. Clara Viñas, Prof. Dr. Francesc Teixidor

Institut de Ciències dels Materials de Barcelona, CSIC

Campus UAB, 08193 Bellaterra (Spain)

E-mail: teixidor@icmab.es
}

Supporting information for this article is given via a link at the end of the document.
$\mathrm{P}, \mathrm{N}$, or other incorporating transition or lanthanide metal fragments. Consequently, the icosahedron or bicapped square antiprism are very relevant geometrical features in $\mathrm{BHs}$ and, by extension, to other areas in which clusters are significant, e.g. Zintl phases.

In the last few years, we have given evidence that the concept of aromaticity, in terms of planar or tridimensional aromaticity, was not too distant, and that most probably $\pi$-aromaticity and $3 \mathrm{D}$ aromaticity were based on the same grounds. ${ }^{[4]}$ This is why we named them as the two sides of the same coin. ${ }^{[4 b]}$ To reach such conclusion we compared the conventional $(4 n+2) \pi$ planar organic cyclic compounds with closo BHs. The aromaticity properties of planar organic cyclic compounds had been demonstrated by their stability, hydrogenation experimental studies, substitution but not addition reactivity, ${ }^{1} \mathrm{H}$-NMR downfield shift of peripheral protons vs. protons in alkene compounds, and by structural criteria fundamentally based on the equalization of bond lengths, energy criteria based on the aromatic stabilization energies, and magnetic and electronic criteria strongly based on a theoretical standpoint. ${ }^{[5]}$ The main methods utilized as magnetic criteria ${ }^{[5 \mathrm{~d}]}$ were aromatic ring current shielding (ARCS), ${ }^{[6]}$ nucleusindependent chemical shifts (NICS), ${ }^{7]}$ and mapping ring currents ${ }^{[8]}$ As electronic indices, ${ }^{[5]}$ we can mention the fluctuation aromaticity index $(\mathrm{FLU})^{[9]}$ and the multicenter electron sharing indices $(\mathrm{MCl}) .{ }^{[10]}$

Thus, aromatic organic compounds are the paradigm of what chemists expect in one aromatic molecule, despite the difficulties in finding an appropriate definition of what the term implies. Therefore $(4 n+2) \pi$ planar organic cyclic compounds have the necessary experimental and theoretical support to be the archetypes of what "aromaticity" may indicate. On the other hand closo BHs that geometrically have the shape of deltahedra have been demonstrated, mostly by the NICS magnetic criteria, ${ }^{[1 a, 11]}$ to be aromatic. This fact is also sustained by reactivity, mainly substitution vs. addition, stability criteria, and equalization of bond lengths. ${ }^{\left[1 a,{ }^{12]}\right.}$ Closo $\mathrm{BHs}$ respond to the formula $\left[\mathrm{B}_{\mathrm{n}} \mathrm{H}_{\mathrm{n}}\right]^{2-}, \mathrm{n}=5$ to 12 and are electronically interpreted by Wade's ${ }^{[13]}$ counting rule $2 n+2$ or by Mingos' rule that is $4 n+2 \cdot{ }^{[14]}$ Both rules are equivalent. Wade's rule refers to the skeletal electron pairs, whereas Mingos' rule also incorporates the exo electron pairs corresponding to the $\mathrm{B}-\mathrm{H}$ bonds, thus referring to the total number of valence electrons (TNVEs). The meaning of $n$ in Hückel's ${ }^{[15]}$ or Wade-Mingos rule ${ }^{[13-}$ ${ }^{14]}$ is totally different: in Hückel's, $\mathrm{n}$ has no relation with the structure, whereas in Wade-Mingos rules indicates the number of vertices in the deltahedron. ${ }^{[16]}$

Therefore we had at hand two geometrically and pictorially very distinct type of compounds, both of them aromatic, both satisfying nominal $4 n+2$ electron counting rules but one having $\pi$-aromaticity and the latter 3D-aromaticity. The question that arose was: were they in reality so different? We have recently shown that they are very much related by the number of valence electrons (VE) in a confined space (CS), and by applying the electronic confined space analogy (ECSA) method it was possible to bridge fundamental aromatic hydrocarbons (HCs) with closo $\mathrm{BH}$ clusters. $^{[4 a]}$ The ECSA method ${ }^{[4 a]}$ was originally intended to be a graphical method by which it was possible, starting from a 
bidimensional model compound, to derive a tridimensional cluster. ${ }^{[17]}$ The method consists in: 1) state the model organic compound; 2) define its confined space $(c S)$ as the number of electrons enclosed in the ring of carbon atoms; 3 ) transmute each carbon atom into a boron atom and one electron $\left.(e T) ;{ }^{[18]} 4\right)$ replace extra electrons by sacrificial atoms ( $s A)$; and 5 ) generate the new $\mathrm{BH}$ compound by structural relaxation $(s \mathrm{R})$. Throughout the whole process, the number of valence electrons in the corresponding confined space remains unaltered. It must be mentioned that Jemmis et al. made a different proposal to connect $\mathrm{BHs}$ and $\mathrm{HCs}$ that does not keep the total number of valence electrons constant. [19]

Application of the ECSA method turned out to be very practical for small organic/boron hydride molecules/clusters, and laid the foundations for the application to larger clusters as those analyzed in this work. It did not work only for aromatic organic molecules but also for non-aromatic. In this way, it was shown that $\mathrm{C}_{2} \mathrm{H}_{4}$ was analog of $\mathrm{B}_{2} \mathrm{H}_{6}$, that $\mathrm{C}_{2} \mathrm{H}_{6}$ was analog of $\left[\mathrm{B}_{2} \mathrm{H}_{7}\right]^{-}$, that $\mathrm{C}_{4} \mathrm{H}_{10}$ was analog of $\mathrm{B}_{5} \mathrm{H}_{11}$, or that $\mathrm{C}_{4} \mathrm{H}_{8}$ was analog of $\mathrm{B}_{5} \mathrm{H}_{9}$, among other cases discussed. ${ }^{[4 a]}$ And in what concerns aromatics, it was shown that $\left[\mathrm{C}_{4} \mathrm{H}_{4}\right]^{2-}$ was analog of $\left[\mathrm{B}_{5} \mathrm{H}_{5}\right]^{2-}$, $\left[\mathrm{C}_{5} \mathrm{H}_{5}\right]^{-}$of $\left[\mathrm{B}_{6} \mathrm{H}_{6}\right]^{2-}$ $\mathrm{C}_{6} \mathrm{H}_{6}$ of $\left[\mathrm{B}_{7} \mathrm{H}_{7}\right]^{2-}$, or $\left[\mathrm{C}_{7} \mathrm{H}_{7}\right]^{+}$of $\left[\mathrm{B}_{8} \mathrm{H}_{8}\right]^{2-} \cdot{ }^{2}{ }^{46]}$ Remarkably, ECSA provides the correct structures of the targeted compounds after application of the structural relaxation and considering the most stable geometries in coordination compounds. For instance, in the analogy of $\left[\mathrm{C}_{5} \mathrm{H}_{5}\right]^{-}$being converted into $\left[\mathrm{B}_{6} \mathrm{H}_{6}\right]^{2-}$, just before the $s R$ process the graphical step produces a pentagonal pyramid, however this is not the most stable arrangement for a coordination six surrounding in coordination chemistry; it is the octahedron. Therefore the $s R$ process led to an octahedron for $\left[\mathrm{B}_{6} \mathrm{H}_{6}\right]^{2-}$ with octahedral aromaticity. ${ }^{[20]}$ Another example is $\left[\mathrm{B}_{8} \mathrm{H}_{8}\right]^{2-}$; again the graphical step just before the $\mathrm{sR}$ produces an heptagonal pyramid but this is not the most stable structure for coordination eight; the most usual ones are cubic, square antiprism, dodecahedron, and hexagonal bipyramid. Taking into account that the boranes produce triangular faces (with some exceptions like in tetraborane, ${ }^{[21]} \mathrm{B}_{4} \mathrm{H}_{10}$ ) the two first are immediately discarded as they have square faces; for a different reason the hexagonal bipyramid is also discarded as it would imply two boron atoms with an in-cluster connectivity of six, whereas all other boron atoms would have a connectivity of four. This leaves the dodecahedron with four vertexes of in-cluster connectivity four and four vertexes of connectivity five as the most plausible structure, as it is the case. So, the utility of ECSA was highlighted in our previous works. ${ }^{[4]}$ In the present work, our aim is to extend the application of ECSA to medium and large $\mathrm{BH}$ clusters, specifically to bicapped structures (from $\left[\mathrm{B}_{10} \mathrm{H}_{10}\right]^{2-}$ to $\left[\mathrm{B}_{14} \mathrm{H}_{14}\right]^{2-}$ ) but also to those presenting three parallel planes (from $\left[\mathrm{B}_{15} \mathrm{H}_{15}\right]^{2-}$ to $\left[\mathrm{B}_{19} \mathrm{H}_{19}\right]^{2-}$ ). As we will show later, application of ECSA to medium and large boron clusters allows us to classify closo boranes in three categories depending on their geometrical complexity.

\section{Results and Discussion}

Therefore the ECSA method leads to the analog $\mathrm{BH}$ just with careful visual inspection of the model compound, however this turned not to be so simple with targeted molecules having two belts of atoms. To exemplify the case, the examples for $\left[\mathrm{B}_{10} \mathrm{H}_{10}\right]^{2-}$ and $\left[\mathrm{B}_{12} \mathrm{H}_{12}\right]^{2-}$ are included.

$\left[\mathrm{B}_{10} \mathrm{H}_{10}\right]^{2-}$ boron hydride. As said above, $\left[\mathrm{B}_{10} \mathrm{H}_{10}\right]^{2-}$ is remarkably aromatic, in agreement with its derivatization chemistry, its stability, and negative NICS values; but there are several options to guess its organic model compound. Up to now, the common way to apply ECSA has been from the organic model to the inorganic target. However, for large clusters, to reach its organic analogue, we needed to go the other way around with the aim to explore which organic molecules could be compatible with the cluster structure. In other words, we needed to produce a retro ECSA, rECSA. This has been exemplified in Figure 1, in which starting from the octahedral $\left[\mathrm{B}_{6} \mathrm{H}_{6}\right]^{2-}$, the planar $(4 n+2) \pi$ cyclopentadienyl anion $\left[\mathrm{C}_{5} \mathrm{H}_{5}\right]^{1-}$ is generated. For this case the procedure can be applied easily and the correspondence 3Daromatic $\mathrm{BH}$ leading to $2 \mathrm{D}$-aromatic hydrocarbon is easily traced. The aromaticity of both compounds was previously proven by ourselves with $\left[\mathrm{B}_{6} \mathrm{H}_{6}\right]^{2-}(\mathrm{NICS}(0)=-31.0 \mathrm{ppm})$ and $\left[\mathrm{C}_{5} \mathrm{H}_{5}\right]^{1-}$ $(\operatorname{NICS}(0)=-12.7 \mathrm{ppm}) .^{[4 \mathrm{~b}]}$

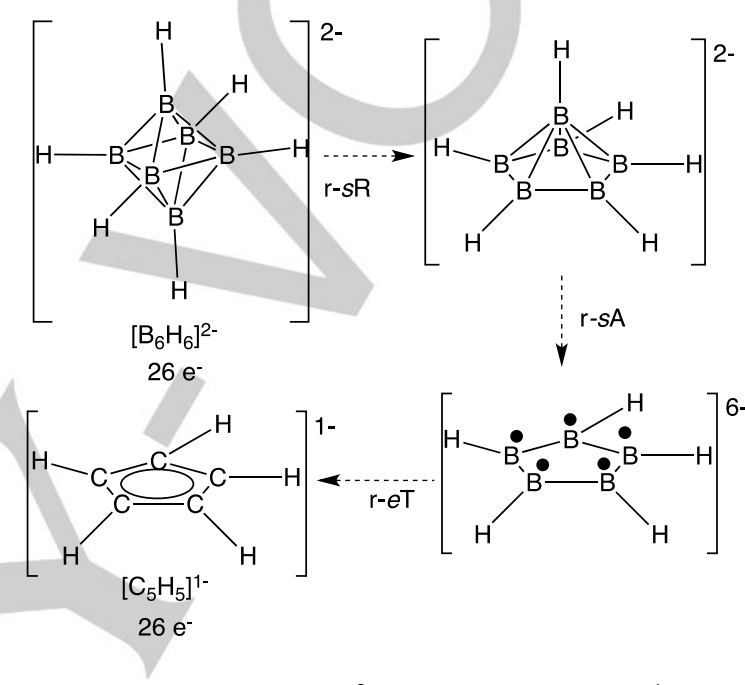

Figure 1. rECSA applied to $\left[\mathrm{B}_{6} \mathrm{H}_{6}\right]^{2-}$ to get hydrocarbon $\left[\mathrm{C}_{5} \mathrm{H}_{5}\right]^{1-}$.

Table 1. Calculated NICS values $[p p m]$ for $\left[\mathrm{B}_{10} \mathrm{H}_{10}\right]^{2-}$ and $\left[\mathrm{B}_{12} \mathrm{H}_{12}\right]^{2-}$ and their equivalent [n]-annulenes.

\begin{tabular}{lrrr}
\hline Compound & Ring & NICS(0) & NICS(0) $\mathbf{z z}$ \\
\hline$\left[\mathrm{B}_{10} \mathrm{H}_{10}\right]^{2-}$ & $4-\mathrm{MR}$ & -33.7 & -45.1 \\
& $3-\mathrm{MR}$ & -46.1 & -53.1 \\
{$\left[\mathrm{C}_{8} \mathrm{H}_{8}\right]^{2-}$} & $8-\mathrm{MR}$ & -11.9 & -10.6 \\
& & & \\
{$\left[\mathrm{~B}_{12} \mathrm{H}_{12}\right]^{2-}$} & $5-\mathrm{MR}$ & -34.6 & -29.0 \\
& $3-\mathrm{MR}$ & -48.3 & -49.2 \\
$\mathrm{C}_{10} \mathrm{H}_{10}{ }^{[a]}$ & $10-\mathrm{MR}$ & -13.7 & -38.7 \\
tctcc-C & $6-\mathrm{MR}$ & 0.9 & -13.8 \\
\hline
\end{tabular}

[a] All cis planar isomer.

When we apply rECSA to the two belts $\left[\mathrm{B}_{10} \mathrm{H}_{10}\right]^{2-}$ boron hydride with a bicapped square antiprism geometry, one possible mode organic molecule could be the 8 -membered ring $\left[\mathrm{C}_{8} \mathrm{H}_{8}\right]^{2-}$, that also possesses 42 VE like $\left[\mathrm{B}_{10} \mathrm{H}_{10}\right]^{2-}$. Thus, from $\left[\mathrm{B}_{10} \mathrm{H}_{10}\right]^{2-}$ we get through (retro)structural relaxation ( $r-s R$ ) an 8-membered ring (8$\mathrm{MR}$ ) with two axial $\mathrm{BH}$ groups pointing in the same direction (see Figure 2). The next two steps: (retro)sacrificial atom ( $r-s A)$ and (retro)electronic transmutation ( $r-e T)$ drive to the proposed $\left[\mathrm{C}_{8} \mathrm{H}_{8}\right]^{2-}$ hydrocarbon equivalent. This equivalence is supported by magnetic aromaticity index NICS. $\left[\mathrm{B}_{10} \mathrm{H}_{10}\right]^{2-}$ presents $\mathrm{NICS}(0)=-$ $33.7 \mathrm{ppm}$ (see Table 1) for any of the two central 4-MRs of this bicapped cluster, and the 3-MRs are also clearly aromatic $(\operatorname{NICS}(0)=-46.1 \mathrm{ppm})$. On the other hand, NICS also assigns a clear aromatic character to $\left[\mathrm{C}_{8} \mathrm{H}_{8}\right]^{2-}$ with $\mathrm{NICS}(0)=-11.9 \mathrm{ppm} .{ }^{[4 \mathrm{~b}]}$ 
$\left[\mathrm{B}_{12} \mathrm{H}_{12}\right]^{2-}$ boron hydride. The situation for $\left[\mathrm{B}_{12} \mathrm{H}_{12}\right]^{2-}$ is similar to that for $\left[\mathrm{B}_{10} \mathrm{H}_{10}\right]^{2-}$, however $\left[\mathrm{B}_{12} \mathrm{H}_{12}\right]^{2-}$ is in every way the paradigm of tridimensional aromaticity in the way benzene is the paradigm of $\pi$-aromaticity. Therefore, it is expected that its analogue in organic chemistry is also a highly aromatic compound. In this way, by applying the rECSA method, the hydrocarbon $\mathrm{C}_{10} \mathrm{H}_{10}$ is generated, with $50 \mathrm{VE}$ like for $\left[\mathrm{B}_{12} \mathrm{H}_{12}\right]^{2-}$. In Figure 3, we observe how 10-MR $\mathrm{C}_{10} \mathrm{H}_{10}$ is obtained by following the proposed rECSA steps as for $\left[\mathrm{B}_{10} \mathrm{H}_{10}\right]^{2}$. Thus, from $\left[\mathrm{B}_{12} \mathrm{H}_{12}\right]^{2-}$ through (retro)structural relaxation an intermediate open cluster is obtained, which is $154 \mathrm{kcal} \mathrm{mol}^{-1}$ higher in energy than closo $\left[\mathrm{B}_{12} \mathrm{H}_{12}\right]^{2-}$, thus proving again the extremely high stability of the latter. It consists of a 10-MR with two axial $\mathrm{BH}$ groups pointing in the same direction, as for the previous case. The following $r-s A$ and $r-e T$ steps drive to the proposed hydrocarbon $\mathrm{C}_{10} \mathrm{H}_{10}$.

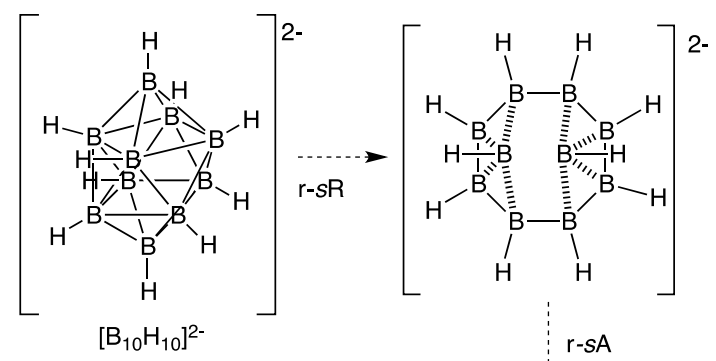<smiles></smiles>

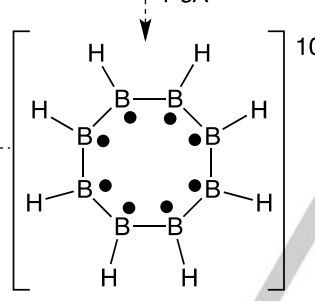

$10-$ with large bond length alternation. ${ }^{[22]}$ Aromaticity is recovered when the $10-M R$ is forced to be almost planar like in 1,6methano[10]annulene ${ }^{[23]}$ (the $\operatorname{NICS}(0)$ value calculated in the center of one of the two 6-MRs is $-14.8 \mathrm{ppm}$, and in the center of the large $10-\mathrm{MR}$ is $-26.8 \mathrm{ppm}$ ). Similarly, in a recent work by $\mathrm{Xi}$ et al., ${ }^{[24]}$ it has been shown that a series of synthesized dicupra[10]annulenes, which do not have the $\mathrm{H} \cdots \mathrm{H}$ steric repulsion present in trans,cis,trans,cis, cis-cyclodecapentaene, are almost planar and aromatic. To confirm further the aromaticity of trans,cis,trans,cis,cis-cyclodecapentaene, we have performed the following gedankenexperiment. We have removed these two out-of-plane hydrogen atoms and built the singlet biradical $\mathrm{C}_{10} \mathrm{H}_{8}$. Geometry optimization of this structure drives to closed-shell naphthalene, which is clearly aromatic $(\mathrm{NICS}(0)=-8.5 \mathrm{ppm}$ in the center of one of the 6-MRs). Just for comparison, the same biradical has been analyzed in its triplet state, giving rise to a stationary point that is clearly antiaromatic $(\operatorname{NICS}(0)=16.3 \mathrm{ppm})$ as expected from Baird's rule, ${ }^{[25]}$ and it is $62.3 \mathrm{kcal} \mathrm{mol}^{-1}$ higher in energy as compared to naphthalene.

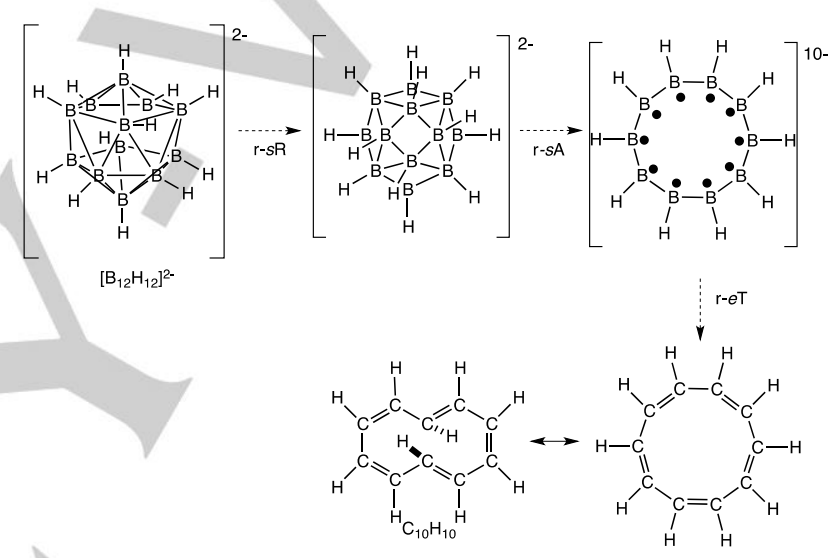

Figure 3. $r E C S A$ equivalence between $\left[\mathrm{B}_{12} \mathrm{H}_{12}\right]^{2-}$ and $\mathrm{C}_{10} \mathrm{H}_{10}$.

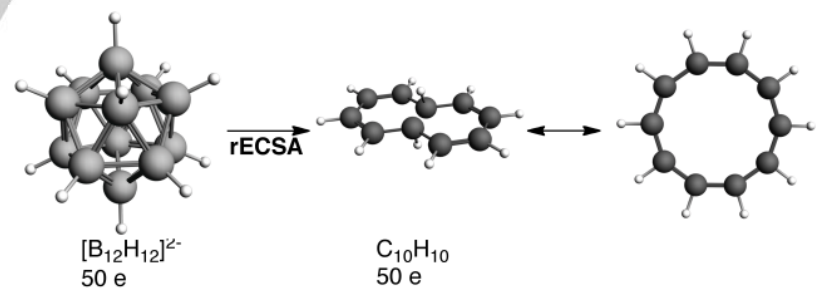

Thus, for both $3 \mathrm{D}$ aromatic bicapped boron clusters $\left[\mathrm{B}_{10} \mathrm{H}_{10}\right]^{2-}$ and $\left[\mathrm{B}_{12} \mathrm{H}_{12}\right]^{2-}$ we have established the connection with two aromatic planar hydrocarbons, $\mathrm{C}_{8} \mathrm{H}_{8}{ }^{2-}$ and $\mathrm{C}_{10} \mathrm{H}_{10}$, respectively.

Planar analogs of $\left[\mathrm{B}_{12} \mathrm{H}_{12}\right]^{2-}$ and $\left[\mathrm{B}_{10} \mathrm{H}_{10}\right]^{2-}$. In line with what we have discussed above for the most representative $\left[\mathrm{B}_{12} \mathrm{H}_{12}\right]^{2-}$ and $\left[\mathrm{B}_{10} \mathrm{H}_{10}\right]^{2-}$ clusters, closo boranes all have the formula $\left[\mathrm{B}_{\mathrm{m}} \mathrm{H}_{\mathrm{m}}\right]^{2-}$, and for the smaller boron clusters we have observed through the ECSA method that their organic analogs also match with a formula $\left[\mathrm{C}_{\mathrm{p}} \mathrm{H}_{\mathrm{p}}\right]^{\mathrm{y}}$, so to obey the $(4 n+2) \pi$ Hückel formula. In this way $\left[\mathrm{B}_{5} \mathrm{H}_{5}\right]^{2-},\left[\mathrm{B}_{6} \mathrm{H}_{6}\right]^{2-},\left[\mathrm{B}_{7} \mathrm{H}_{7}\right]^{2-},\left[\mathrm{B}_{8} \mathrm{H}_{8}\right]^{2-}$, and $\left[\mathrm{B}_{9} \mathrm{H}_{9}\right]^{2-}$ are linked with $\left[\mathrm{C}_{4} \mathrm{H}_{4}\right]^{2-},\left[\mathrm{C}_{5} \mathrm{H}_{5}\right]^{-}, \mathrm{C}_{6} \mathrm{H}_{6},\left[\mathrm{C}_{7} \mathrm{H}_{7}\right]^{+}$, and $\left[\mathrm{C}_{8} \mathrm{H}_{8}\right]^{2+}$, respectively, that are all of them hydrocarbons with $6 \pi$ electrons obeying Hückel's rule with $\mathrm{n}=1$. When we get into larger boranes, among them $\left[\mathrm{B}_{10} \mathrm{H}_{10}\right]^{2-}$ and $\left[\mathrm{B}_{12} \mathrm{H}_{12}\right]^{2-}$, the organic aromatic analog type $=0.9 \mathrm{ppm}$ ) because of a combination of steric and angular strains that switch off $\pi$ conjugation and lead to a non-planar structure 
changes, as seen through the rECSA method indicated above, and one enters in the $n=2$ value for Hückel's rule. Interestingly, the $-2,-1,0,+1$ and +2 charge sequence observed for the smaller boranes in the $\left[\mathrm{C}_{\mathrm{p}} \mathrm{H}_{\mathrm{p}}\right]^{y}$ series, corresponding to the organic analogs, is observed again. Thus, $\left[\mathrm{B}_{10} \mathrm{H}_{10}\right]^{2-},\left[\mathrm{B}_{11} \mathrm{H}_{11}\right]^{2-},\left[\mathrm{B}_{12} \mathrm{H}_{12}\right]^{2-}$, $\left[\mathrm{B}_{13} \mathrm{H}_{13}\right]^{2-}$, and $\left[\mathrm{B}_{14} \mathrm{H}_{14}\right]^{2-}$ are connected with $\left[\mathrm{C}_{8} \mathrm{H}_{8}\right]^{2-}$, $\left[\mathrm{C}_{9} \mathrm{H}_{9}\right]^{-}$, $\mathrm{C}_{10} \mathrm{H}_{10},\left[\mathrm{C}_{11} \mathrm{H}_{11}\right]^{+}$, and $\left[\mathrm{C}_{12} \mathrm{H}_{12}\right]^{2+}$, respectively, with $10 \pi$-electrons and $n=2$. The $2+$ charge indicates that this series has reached an end, and that a new series with $\mathrm{n}=3$ can be generated. In it we find $\left[\mathrm{B}_{15} \mathrm{H}_{15}\right]^{2-},\left[\mathrm{B}_{16} \mathrm{H}_{16}\right]^{2-},\left[\mathrm{B}_{17} \mathrm{H}_{17}\right]^{2-},\left[\mathrm{B}_{18} \mathrm{H}_{18}\right]^{2-}$, and $\left[\mathrm{B}_{19} \mathrm{H}_{19}\right]^{2-}$ matching $\left[\mathrm{C}_{12} \mathrm{H}_{12}\right]^{2-},\left[\mathrm{C}_{13} \mathrm{H}_{13}\right]^{-}, \mathrm{C}_{14} \mathrm{H}_{14},\left[\mathrm{C}_{15} \mathrm{H}_{15}\right]^{+}$, and $\left[\mathrm{C}_{16} \mathrm{H}_{16}\right]^{2+}$, respectively (see Figure 4). In Figure 4 , to make a uniform comparison, we have considered only all cis [n]annulenes, despite they are not the most stable isomers. In addition, for the $\left[\mathrm{B}_{n} \mathrm{H}_{n}\right]^{2-}$ species with $\mathrm{n}=15-19$, we have make the assumption that the most stable closo $\mathrm{BH}$ isomer has the same structure as the most stable corresponding closo carborane. ${ }^{[26]}$

Therefore the list of closo $\mathrm{BH}$ clusters, $\left[\mathrm{B}_{\mathrm{m}} \mathrm{H}_{\mathrm{m}}\right]^{2-}$, can be categorized also with Hückel's $n$ value associated with their organic analogs from $5 \leq m \leq 9$ for $n=1$, from $10 \leq m \leq 14$ for $n=2$, and from $15 \leq m \leq 19$ for $n=3$. Furthermore, with respect to the equivalence between $\left[\mathrm{B}_{m} \mathrm{H}_{m}\right]^{2-}$ and $\left[\mathrm{C}_{p} \mathrm{H}_{p}\right]^{y}$ formulae, it can be easily observed that for $n=1, p=m-1$; for $n=2, p=m-2$; and for $n=3$, $\mathrm{p}=\mathrm{m}-3$.

Noteworthy is: i) If $\left[\mathrm{B}_{4} \mathrm{H}_{4}\right]^{2-}$ existed it would be the last member of the series (its $\mathrm{HC}$ analog would have charge 2+) for Hückel's $\mathrm{n}=0$, but $\left[\mathrm{B}_{4} \mathrm{H}_{4}\right]^{2-}$ is not experimentally known. Computed $\left[\mathrm{B}_{4} \mathrm{H}_{4}\right]^{2-}$ adopts a butterfly $D_{2 d}$ geometry $\left(D_{2 d}\right.$ geometry can be preferred over $\mathrm{D}_{4 \mathrm{~h}}$ due to the presence of stabilizing 1,3 -overlaps ${ }^{[27]}$ ), thus it is not a tetrahedron cluster as we would expect, and it is aromatic on the basis of NICS (NICS $(0)=-9.5 \mathrm{ppm})$; further, its analogue $\left[\mathrm{C}_{4} \mathrm{H}_{4}\right]^{2+}$ is neither known in organic chemistry, but its computed geometry is also of $\mathrm{D}_{2 \mathrm{~d}}$ symmetry, and aromatic as well $(\operatorname{NICS}(0)=-7.8 \mathrm{ppm})$. It may be mentioned in passing that very recently a triboracyclopropenyl dianion, $\left[\mathrm{B}_{3} \mathrm{R}_{3}\right]^{2-}$, analog of $\mathrm{C}_{3} \mathrm{H}_{3}{ }^{+}$ and Hückel aromatic with $n=0$, has been reported. ${ }^{[28]}$ ii) The more stable boron hydrides in the series for $n=1$ and 2 are these whose organic analog has a zero charge, or close to it, e.g. $\left[\mathrm{B}_{6} \mathrm{H}_{6}\right]^{2-}$ for $\left[\mathrm{C}_{5} \mathrm{H}_{5}\right]^{-}$and $\left[\mathrm{B}_{7} \mathrm{H}_{7}\right]^{2-}$ for $\mathrm{C}_{6} \mathrm{H}_{6}(\mathrm{n}=1)$ and $\left[\mathrm{B}_{12} \mathrm{H}_{12}\right]^{2-}$ for $\mathrm{C}_{10} \mathrm{H}_{10}(\mathrm{n}=2)$. iii) Boron experimental chemistry beyond the icosahedron is extremely hard and very few examples based on only main group elements, number of vertexes 13 and 14, have been experimentally produced and, in low yields. ${ }^{16,29]}$ Therefore experimental physical details are not available, however and based on the ECSA model these large clusters should be stable, particularly $\left[\mathrm{B}_{17} \mathrm{H}_{17}\right]^{2-}$ whose analog $\mathrm{C}_{14} \mathrm{H}_{14}$ has charge 0 . In 1998 Schleyer et al. published[1 ${ }^{11 a}$ that $\left[\mathrm{B}_{17} \mathrm{H}_{17}\right]^{2-}$ had even a more negative NICS value than $\left[\mathrm{B}_{12} \mathrm{H}_{12}\right]^{2-}$, and that bond length alternation for $\left[\mathrm{B}_{17} \mathrm{H}_{17}\right]^{2-}$ was the second smallest after the perfect platonic solid abiding $\left[\mathrm{B}_{12} \mathrm{H}_{12}\right]^{2-}$.

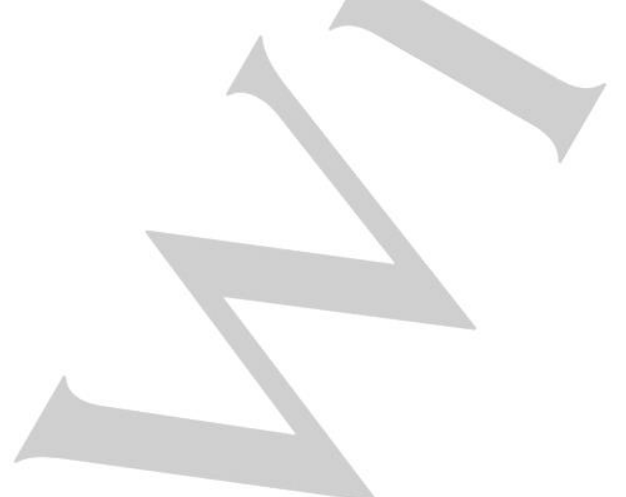

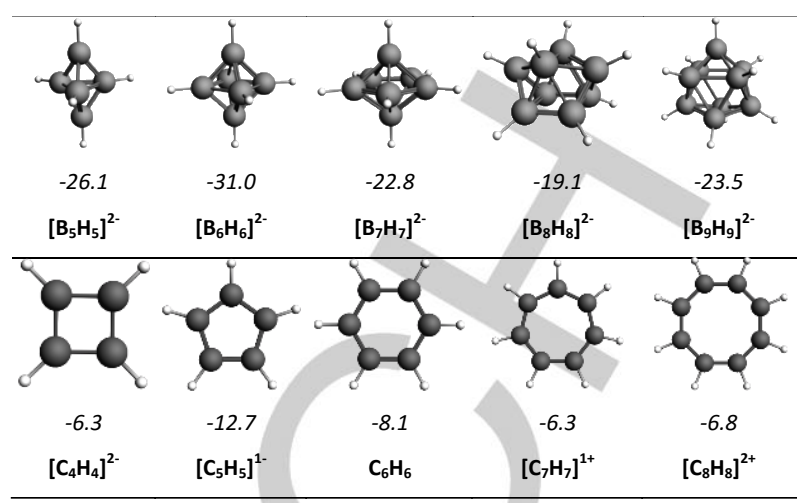

a) $n=1$ in $4 n+2$ Hückel's rule

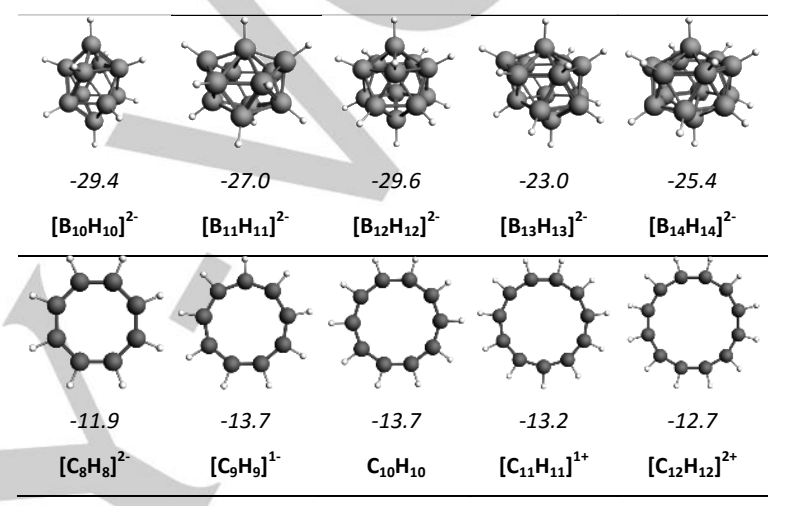

b) $n=2$ in $4 n+2$ Hückel's rule

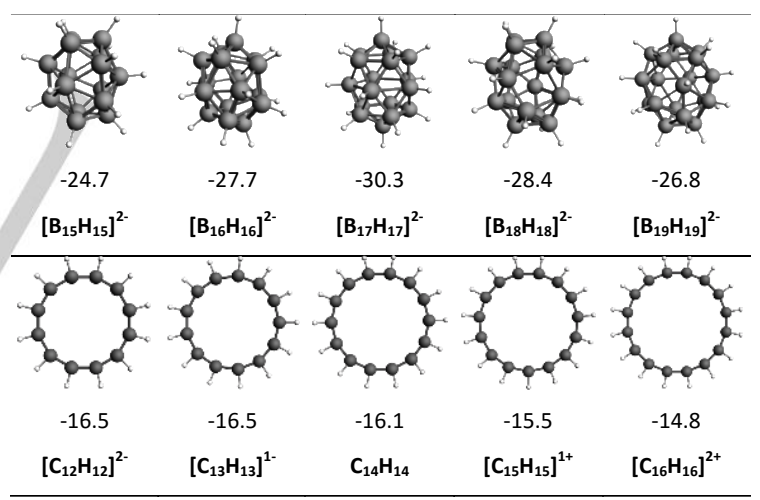

c) $n=3$ in $4 n+2$ Hückel's rule

Figure 4. Equivalence between boron hydrides and hydrocarbons based on Hückel's rule. Below each figure NICS(0) value (in italics, in ppm) is included, calculated at the geometrical center of each system.

Comments on the boron hydride closo clusters abiding the Hückel series $n=1,2$, and 3 . As indicated above, each series consists of five members that correspond to the charges $-2,-1,0$, +1 and +2 of the organic analog for the $6 \pi$ electrons (series $n=$ 1 ), $10 \pi$ electrons (series $n=2$ ), and $14 \pi$ electrons (series $n=3$ ).

The first member of the series $n=1$ is $\left[\mathrm{C}_{4} \mathrm{H}_{4}\right]^{2-}$, analog of $\left[\mathrm{B}_{5} \mathrm{H}_{5}\right]^{2-}$ that is the first $\mathrm{BH}$ cluster acknowledged. $\left[\mathrm{B}_{5} \mathrm{H}_{5}\right]^{2-}$ is the first of five members that form the smallest and structurally most simple BHs, whose members range from $\left[\mathrm{B}_{5} \mathrm{H}_{5}\right]^{2-}$ to $\left[\mathrm{B}_{9} \mathrm{H}_{9}\right]^{2-}$. In this series, $\left[\mathrm{B}_{7} \mathrm{H}_{7}\right]^{2-}$ corresponds to an analog with charge $0, \mathrm{C}_{6} \mathrm{H}_{6}$, 
and characteristically has one pentagonal plane perpendicular to the main axis (see Figure 4).

The second series, $n=2$, is represented by a higher degree of structural complexity. In this series, $\left[\mathrm{B}_{12} \mathrm{H}_{12}\right]^{2-}$ corresponds to an analog with charge $0, \mathrm{C}_{10} \mathrm{H}_{10}$, and characteristically has two pentagonal parallel planes perpendicular to the main axis (see Figure 4).

The third series, $n=3$, is represented by even a higher degree of structural complexity. In this series, $\left[\mathrm{B}_{17} \mathrm{H}_{17}\right]^{2-}$ corresponds to an analog with charge $0, \mathrm{C}_{14} \mathrm{H}_{14}$, and characteristically has three pentagonal parallel planes perpendicular to the main axis (see Figure 4).

Therefore, for the series 1,2 , and 3 the central $\mathrm{BH}$ cluster member that corresponds to a charge 0 of the organic analog has 1,2 , and 3 pentagonal layers, respectively, perpendicular to the main axis.

What makes closo BHs so keen to be aromatic? When comparing $\mathrm{BHs}$ from $\left[\mathrm{B}_{5} \mathrm{H}_{5}\right]^{2-}$ to $\left[\mathrm{B}_{17} \mathrm{H}_{17}\right]^{2-}$ and beyond in steps of one unit, to say $\left[\mathrm{B}_{5} \mathrm{H}_{5}\right]^{2-},\left[\mathrm{B}_{6} \mathrm{H}_{6}\right]^{2-},\left[\mathrm{B}_{7} \mathrm{H}_{7}\right]^{2-}, \ldots \ldots\left[\mathrm{B}_{10} \mathrm{H}_{10}\right]^{2-}, \ldots\left[\mathrm{B}_{12} \mathrm{H}_{12}\right]^{2-}$ ,..[ $\left[\mathrm{B}_{14} \mathrm{H}_{14}\right]^{2-}, \ldots .\left[\mathrm{B}_{17} \mathrm{H}_{17}\right]^{2-}, \ldots \ldots$ one notices that all are aromatic. Conversely, when comparison is made to the stoichiometrically similar annulenes $\mathrm{C}_{4} \mathrm{H}_{4}, \quad \mathrm{C}_{5} \mathrm{H}_{5}, \quad \mathrm{C}_{6} \mathrm{H}_{6}, \quad \ldots \mathrm{C}_{8} \mathrm{H}_{8}, \quad \ldots \mathrm{C}_{10} \mathrm{H}_{10}$, $\ldots \mathrm{C}_{14} \mathrm{H}_{14} \ldots$ one notices that few of them fulfil the Hückel's rule, and in some of the cases the reason why are not aromatic is due to the steric repulsion caused by the internal hydrogen atoms.

One immediate answer to the question above relates to the fact that all hydrogen atoms in $\mathrm{BHs}$ are outwards and that due to their radial dispersion the steric repulsions are negligible. However, more relevant to the question are the electronic requirements. Conjugated organic compounds are severely restricted to the planarity of the ring and the fulfilment to the Hückel $(4 n+2) \pi$ rule, that means that only these annulenes subjected to the magic numbers $2,6,10,14 \ldots$ will satisfy the condition by providing closed-shell electronic configurations. Interestingly here is the difference between each pair of the members of this sequence, four. Four are the number of electrons. If we pay attention to the stepwise sequence of $\left[\mathrm{B}_{n} \mathrm{H}_{n}\right]^{-}$to say between $\left[\mathrm{B}_{5} \mathrm{H}_{5}\right]^{2-}$ and $\left[\mathrm{B}_{6} \mathrm{H}_{6}\right]^{2-}$ or between $\left[\mathrm{B}_{10} \mathrm{H}_{10}\right]^{2-}$ and $\left[\mathrm{B}_{11} \mathrm{H}_{11}\right]^{2-}$ the difference in the TNVE is again four.

Therefore, four seems to be the magic number. Four electrons is the number of VE brought by each new $\mathrm{BH}$ unit, a facet not fulfilled by any other catenating element, e.g. $\mathrm{CH}$ would bring 5 VE.

Further, each new BH contributes four valence atomic orbitals to the cluster, three from the boron and one from the hydrogen, the fourth $\mathrm{B}$ atomic orbital is to accommodate with all fourth orbital coming from each contributing $\mathrm{BH}$, the two extra electrons indicated by the charge. Therefore, the four bonding atomic orbitals produce two bonding molecular orbitals that are filled by two pairs of contributing electrons, always producing a closedshell electronic configuration.

\section{Conclusions}

In this work, the ECSA method has been successfully applied to medium and large size boron clusters. In particular, thanks to the confined space concept and to the ECSA method, boron clusters have been categorized into different series according to the $n$ value of the Hückel $(4 n+2) \pi$ rule. The distinct categories studied in this work have been for $n=1,2$, and 3 . Each category increases in geometrical difficulty but, more importantly, it is possible to associate each category with the number of pentagonal layers in the structure perpendicular to the main axis. Category 1 has one pentagonal layer, category 2 has two, and category 3 has three.

The ECSA method has proven by the analogy criterion that every closo boron hydride finds its analogue that satisfies the Hückel $(4 n+2) \pi$ rule. Each category is made of five elements as a consequence of the charge of the organic analogue satisfying the Hückel $(4 n+2) \pi$ rule, and the process is periodic after changing the category.

The ECSA method basically consisted in defining one organic aromatic compound and develop its boron hydride analogue. In this work the opposite method named retro ECSA has been developed to produce the organic analogue of a medium or large closo boron cluster. By applying this retro ECSA method it has been possible to find the organic molecules that are analogues of closo boron hydride clusters. The method has been shown in detail only for $\left[\mathrm{B}_{10} \mathrm{H}_{10}\right]^{2-}$ and for $\left[\mathrm{B}_{12} \mathrm{H}_{12}\right]^{2-}$, but it can be extended to large closo boranes, although in this latter case its application is not as straightforward as it is in small and medium size clusters because the structural relaxation step in some cases does not lead smoothly to the final organic analog. Finally, it has been found that on the basis of NICS aromaticity criterion, the closo boron hydride clusters are as a consequence of their electronic contributions aromatic compounds connected to aromatic archetype hydrocarbons.

\section{Experimental Section}

All calculations were performed with the Gaussian 09 package ${ }^{[30]}$ by using the B3LYP ${ }^{[31]}$ hybrid density functional and the $6-311++G(d, p)$ basis set. ${ }^{[2]}$ The geometry optimizations were carried out without symmetry constraints, and analytical Hessians were computed to characterize the optimized structures as minima (zero imaginary frequencies) or $n$-order saddle points ( $n$ imaginary frequencies). Broken symmetry unrestricted calculations at UB3LYP/6-311++G(d,p) level were performed for singlet biradical and triplet $\mathrm{C}_{10} \mathrm{H}_{8}$ species.

Aromaticity was evaluated by means of the nucleus-independent chemical shift (NICS) [7, 33] proposed by Schleyer and co-workers, as a magnetic descriptor of aromaticity. NICS is defined as the negative value of the absolute shielding computed at a ring center or at some other interesting point of the system. Rings with large negative NICS values are considered aromatic. NICS values were computed using the gaugeincluding atomic orbital method (GIAO). ${ }^{[3]}$ The magnetic shielding tensor was calculated for ghost atoms located at the center of the rings (or polyhedra) determined by the non-weighted mean of the heavy atoms coordinates. These values are denoted as $\operatorname{NICS}(0) .{ }^{[35]}$

\section{Acknowledgements}

This work has been supported by the Ministerio de Economía y Competitividad (MINECO) of Spain (Projects CTQ2014-54306-P and CTQ2013-44670-R) and the Generalitat de Catalunya (projects 2014SGR931 and 2014SGR149, Xarxa de Referència en Química Teòrica i Computacional, and ICREA Academia 2014 prize for M.S.). The EU under the FEDER grant UNGI10-4E-801 (European Fund for Regional Development) has also funded this research.

Keywords: closo boron hydride clusters $•$ [n]annulenes • aromaticity • Hückel's rule • Wade-Mingos' rule 
[1] a) P. v. R. Schleyer, K. Najafian, A. M. Mebel, Inorg. Chem. 1998, 37 6765-6772; b) D. A. Kleier, D. A. Dixon, W. N. Lipscomb, Inorg. Chem. 1978, 17, 166-167; c) W. N. Lipscomb, Science 1966, 373-378; d) E. I. Tolpin, W. N. Lipscomb, J. Am. Chem. Soc. 1973, 95, 2384-2386.

[2] A. R. Pitochelli, F. M. Hawthorne, J. Am. Chem. Soc. 1960, 82, 3228 3229

[3] W. N. Lipscomb, A. R. Pitochelli, M. F. Hawthorne, J. Am. Chem. Soc. 1959, 81, 5833-5834

[4] a) J. Poater, M. Solà, C. Viñas, F. Teixidor, Chem. Eur. J. 2013, 19, 4169 4175; b) J. Poater, M. Solà, C. Viñas, F. Teixidor, Angew. Chem. Int. Ed. 2014, 53, 12191-12195.

[5] a) P. v. R. Schleyer, Chem. Rev. 2005, 105, 3433-3435; b) J. Poater, M. Duran, M. Solà, B. Silvi, Chem. Rev. 2005, 105, 3911-3947; c) F. Feixas, E. Matito, J. Poater, M. Solà, Chem. Soc. Rev. 2015, 44, 6434-6451; d) R. Gershoni-Doranne, A. Stanger, Chem. Soc. Rev. 2015, 44, 65976615.

[6] J. Jusélius, D. Sundhom, Phys. Chem. Chem. Phys. 1999, 1, 3429-3435 P. v. R. Schleyer, C. Maerker, A. Dransfeld, H. Jiao, N. J. R. van Eikema Hommes, J. Am. Chem. Soc. 1996, 118, 6317-6318.

[8] R. W. A. Havenith, J. J. Engelberts, P. W. Fowler, E. Steiner, J. H. van Lenthe, P. Lazzeretti, Phys. Chem. Chem. Phys. 2004, 6, 289-294.

[9] E. Matito, M. Duran, M. Solà, J. Chem. Phys. 2005, 122, 014109.

[10] P. Bultinck, R. Ponec, S. Van Damme, J. Phys. Org. Chem. 2005, 18 706-718.

[11] a) P. v. R. Schleyer, G. Subramanian, A. Dransfeld, J. Am. Chem. Soc 1996, 118, 9988-9989; b) P. v. R. Schleyer, K. Najafian, Inorg. Chem. 1998, 37, 3454-3470; c) Z. F. Chen, R. King, Chem. Rev. 2005, 105 3613-3642.

[12] a) J. Aihara, J. Am. Chem. Soc. 1978, 100, 3339-3342; b) T. M. Krygowski, H. Szatylowicz, O. A. Stasyuk, J. Dominikowska, M. Palusiak, Chem. Rev. 2014, 114, 6383-6422.

[13] a) K. Wade, J. Chem. Soc. D: Chem. Commun. 1971, 792-793; b) K. Wade, Electron-deficient Compounds, Nelson and Sons, Ltd., London, 1971.

[14] a) D. M. P. Mingos Nature Phys. Sci. 1972, 236, 99-102; b) D. M. P. Mingos, Acc. Chem. Res. 1984, 17, 311-319.

[15] E. Hückel, Z. Elektrochemie 1937, 43, 752-788, 827-849.

[16] A. J. Welch, Chem. Comm. 2013, 49, 3615-3616.

[17] a) H. Braunschweig, R. D. Dewhurst, K. Hammond, J. Mies, K. Radacki, A. Vargas, Science 2012, 336, 1420-1422; b) R. N. Grimes, Carboranes, 2on ed., Academic Press, New York, 2011; c) E. Osorio, J. K. Olson, W Tiznado, A. I. Boldyrev, Chem. Eur. J. 2012, 18, 9677-9681; d) H.-J. Zhai, B. Kiran, J. Li, L.-S. Wang, Nature Mater. 2003, 2, 827-833

[18] J. K. Olson, A. I. Boldyrev, Chem. Phys. Lett. 2012, 523, 83-86.

[19] a) E. D. Jemmis, E. G. Jayasree, P. Parameswaran, Chem. Soc. Rev. 2006, 35, 157-168; b) E. D. Jemmis, E. G. Jayasree, Acc. Chem. Res. 2003, 36, 816-824.

[20] O. El Bakouri, M. Duran, J. Poater, F. Feixas, M. Solà, Phys. Chem. Chem. Phys. 2016, DOI: 10.1039/c5cp07011b.
[21] C. J. Dain, A. J. Downs, G. S. Laurenson, D. W. H. Rankin, J. Chem Soc., Dalton Trans. 1981, 472-477.

[22] C. Castro, W. L. Karney, C. M. McShane, R. P. Pemberton, J. Org. Chem. 2006, 71, 3001-3006.

[23] a) R. Bianchi, T. Pilati, M. Simonetta, Acta Cryst. Sect. B 1980, 36, 3146 3148; b) G. F. Caramori, K. T. de Oliveira, S. E. Galembeck, P. Bultinck, M. G. Constantino, J. Org. Chem. 2007, 72, 76-85

[24] J. Wei, Y. Zhang, Y. Chi, L. Liu, W.-X. Zhang, Z. Xi, J. Am. Chem. Soc. 2016, 138, 60-63.

[25] N. C. Baird, J. Am. Chem. Soc. 1972, 94, 4941-4948.

[26] J. Zhang, Z. Lin, Z. Xie, Organometallics 2015, 34, 5576-5588.

[27] a) M. Bremer, P. v. R. Schleyer, U. Fleischer, J. Am. Chem. Soc. 1989 $111,1147-1148 ;$ b) A. A. Fokin, B. Kiran, M. Bremer, X. Yang, H. Jiao, P. v. R. Schleyer, P. R. Schreiner, Chem. Eur. J. 2000, 6, 1615-1628.

[28] T. Kupfer, H. Braunschweig, K. Radacki, Angew. Chem. Int. Ed. 2015 , 54, 15084-15088.

[29] a) A. Burke, D. Ellis, B. T. Giles, B. E. Hodson, S. A. Macgregor, G. M. Rosair, A. J. Welch, Angew. Chem. Int. Ed. 2003, 42, 225-228; b) L. Deng, H.-S. Chan, Z. Xie, Angew. Chem. Int. Ed. 2005, 44, 2128-2131.

[30] M. J. Frisch, G. W. Trucks, H. B. Schlegel, G. E. Scuseria, M. A. Robb J. R. Cheeseman, G. Scalmani, V. Barone, B. Mennucci, G. A. Petersson, H. Nakatsuji, M. Caricato, X. Li, H. P. Hratchian, A. F. Izmaylov, J. Bloino, G. Zheng, J. L. Sonnenberg, M. Hada, M. Ehara, K. Toyota, R. Fukuda, J. Hasegawa, M. Ishida, T. Nakajima, Y. Honda, O. Kitao, H. Nakai, T. Vreven, J. A. Montgomery Jr., J. E. Peralta, F. Ogliaro, M. Bearpark, J. J. Heyd, E. Brothers, K. N. Kudin, V. N. Staroverov, R. Kobayashi, J. Normand, K. Raghavachari, A. Rendell, J. C. Burant, S. S. Iyengar, J. Tomasi, M. Cossi, N. Rega, J. M. Millam, M. Klene, J. E. Knox, J. B. Cross, V. Bakken, C. Adamo, J. Jaramillo, R Gomperts, R. E. Stratmann, O. Yazyev, A. J. Austin, R. Cammi, C. Pomelli, J. W. Ochterski, R. L. Martin, K. Morokuma, V. G. Zakrzewski, G. A. Voth, P. Salvador, J. J. Dannenberg, S. Dapprich, A. D. Daniels, Ö. Farkas, J. B. Foresman, J. V. Ortiz, J. Cioslowski, D. J. Fox, Gaussian 09, Revision A.02 ed., Gaussian, Inc., Pittsburgh, PA, 2009

[31] a) A. D. Becke, J. Chem. Phys. 1993, 98, 5648-5652; b) C. Lee, W. Yang R. G. Parr, Phys. Rev. B 1988, 37, 785-789; c) P. J. Stephens, F. J. Devlin, C. F. Chabalowski, M. J. Frisch, J. Phys. Chem. 1994, 98, 1162311627.

[32] M. J. Frisch, J. A. Pople, J. S. Binkley, J. Chem. Phys. 1984, 80, 3265 3269.

[33] Z. Chen, C. S. Wannere, C. Corminboeuf, R. Puchta, P. v. R. Schleyer, Chem. Rev. 2005, 105, 3842-3888.

[34] K. Wolinski, J. F. Hilton, P. Pulay, J. Am. Chem. Soc. 1990, 112, 8251 8260.

[35] C. Corminboeuf, T. Heine, G. Seifert, P. v. R. Schleyer, J. Weber, Phys. Chem. Chem. Phys. 2004, 6, 273-276. 


\section{Entry for the Table of Contents}

\section{FULL PAPER}

Aromatic closo boron hydride clusters can be categorized into different series according to the $n$ value of the Hückel $(4 n+2) \pi$ rule. This classification follows from the existence of a link between the twodimensional Hückel rule followed by aromatic [n]-annulenes and WadeMingos' rule of three-dimensional aromaticity applied to the aromatic $\left[\mathrm{B}_{\mathrm{n}} \mathrm{H}_{\mathrm{n}}\right]^{2-}$ closo boron hydride clusters.
Jordi Poater, Miquel Solà, * Clara Viñas, and Francesc Teixidor

Page No. - Page No.

Hückel's Rule of Aromaticity Categorizes Aromatic closo Boron Hydride Clusters 